place on the labour ward then the second drill should take place on a maternity ward. In this way the medical staff would be repeating the drill and a new group of midwives would be gaining experience. We aim to have a drill every 3-4 months.

\section{Strategy for change}

Analysis of the simulations identified several problems in the management of patients with eclampsia (box 4), including both errors in the system and errors made by individuals. Significantly, during our first drill there was a failure to apply evidence based principles. Solutions were developed and implemented by senior medical and midwifery staff, and the labour ward risk management group was responsible for disseminating information about the new strategies.

\section{Box 4: Problems identified during drills, and} solutions

- Difficulty summoning senior staff urgently Rapid activation of team through one call from switchboard

- Multiple protocols for managing eclampsia in different clinical areas, many out of date Development and dissemination of an evidence based protocol for eclampsia

- Deficiencies in the skills and knowledge of individuals in the management of eclampsia: positioning of the fitting patient; choice of first line anticonvulsant; safe administration of magnesium Immediate individual feedback and education; didactic instruction on magnesium administration in eclampsia protocol

- Time wasted fetching individual items for management of seizures Creation of strategically placed "eclampsia boxes" containing all necessary equipment and protocol for eclampsia

- Variable presentation of magnesium in drug cupboards

Liaison with pharmacy to ensure consistency of magnesium ampoules supplied

- Confusion about staff roles, resulting in inefficient activity

Clear division of tasks in management protocol

\section{Effects of change}

Repetition of drills in our unit has improved the care of simulated patients with eclampsia. In subsequent drills patient management has followed evidence based practice, with an enhanced level of efficiency. Staff are summoned faster, the resuscitation process is better organised, and drugs are prepared and administered more quickly. These improvements were unlikely to be due to experience gained in previous drills, as few staff participated in more than one drill, but were more likely brought about by the simplification and reduction of tasks required when a patient has a convulsion and increased awareness of all staff about these tasks. Some staff found the drill a useful educational activity; however, it is probably not essential that everyone participates in a drill to improve the standard of care given by a unit as a whole.

\section{Key learning points}

Clinical governance in obstetrics requires the use of risk management strategies

Traditional methods of risk reduction may not be applicable to infrequent yet serious conditions such as eclampsia

On-site simulation of obstetric emergencies allows risks to be identified without exposure of real patients to inadequate care

On-site simulation provides controlled experience for all staff and promotes teamwork practices within a clinical unit

\section{Lessons learnt}

On-site simulation can identify and correct potential deficiencies in the care of patients with eclampsia. This form of risk management may be applied to other emergencies that arise infrequently, in both obstetrics and elsewhere.

Contributors: ST has participated in and coordinates drills, and initiated this article. SN is the lead obstetric anaesthetist in a district hospital, coordinates drills in her unit, and provided the photograph. VC initiated and organises the obstetric emergency drills programme at the Simpson Centre for Reproductive Health, Royal Infirmary of Edinburgh.

Funding: None declared.

Competing interests: None declared.

1 Department of Health. An organisation with a memory. Report of an expert group on learning from adverse events in the NHS, chaired by the Chief Medical Officer. London: Stationery Office, 2000.

2 Confidential Enquiry into Maternal Deaths in the United Kingdom. Why mothers die. London: Royal College of Obstetricians and Gynaecologists, mothers
1999.

3 Royal College of Obstetricians and Gynaecologists. Towards safer childbirth. London; RCOG, 1999.

4 NHS Litigation Authority. Clinical negligence scheme for trusts. Clinical risk management standards for maternity services. London: NHSLA, Aug 2003.

5 Patel RM, Crombleholme WR. Using simulation to train residents in managing critical events. Acad Med 1998;73(5):593.

6 Cro S, King B, Paine P. Practice makes perfect: maternal emergency training. Br J Midwifery 2001;9:492-6.

7 Chopra V, Gesink BJ, De Jong J, Bovil JG, Spierdijk J, Brand R. Does training on an anaesthesia simulator lead to improvement in performance? BrJ Anaesth 1994;73:293-7.

8 Gaba DM, Howard SK, Flanagan B, Smith B, Fish K, Botney R. Assessment of clinical performance during simulated crises using both Assessment of clinical performance during simulated crises using
technical and behavioural ratings. Anesthesiology 1998;89:8-18.

9 Burke C. Scenario training: how we do it and the lessons we have learned. Clin Risk 2003;9:103-6.

10 Walpole R, Clark V. How to organise a major obstetric haemorrhage 'fire-drill:' CPD Anaesthesia 2002;4:15-8.

11 Douglas KA, Redman CWG. Eclampsia in the United Kingdom. BMJ 1994;309:1395-400.

12 Royal College of Obstetricians and Gynaecologists Guideline Management of eclampsia. www.rcog.org.uk/guidelines.asp?PageID =106\& GuidelineID $=9$ (accessed 5 Jan 2004)

13 Duley L. Magnesium sulphate regimens for women with eclampsia: messages from the Collaborative Eclampsia Trial. Br J Obst Gynaecol 1996;103:103-5.

14 Sibai BM. Eclampsia. Maternal-perinatal outcome in 254 consecutive cases. Am J Obstet Gynaecol 1990;163:1049-55. (Accepted 18 November 2003)

\section{Endpiece}

\section{No health foods}

Old people shouldn't eat health foods. They need all the preservatives they can get.

\section{Robert Orben}

Fred Charatan,

retired geriatric physician, Florida 